\title{
the society's awards
}

The Carl-Gustaf Rossby Research Medal comprises a gold medal and a certificate. The medal has on one side the insignia of the Society and on the other side the name of the medal, the name of the recipient and the year. The Award is presented on the basis of outstanding contributions to man's understanding of the structure or behavior of the atmosphere. It represents the highest honor that the Society can bestow upon an atmospheric scientist. The Award may be made annually but the Awards Committee should not hesitate to pass over a year when there is no outstanding nomination.

The Second Half Century Award is the second highest award of the AMS and is given to members for the excellence of their contributions to the geofluid sciences. The award, which was given for the first time at the celebration of the Society's 50th Anniversary, is in the form of a medallion accompanied by a nominal stipend. Not more than three Second Half Century awards are to be given annually to members who shall not be over fifty years of age at the time the awards are to be presented.

The Charles Franklin Brooks Award is made to an individual who has made important contributions to the Society, usually over a period of years. Award is made on occasion, as the circumstances dictate.

The Cleveland Abbe Award for Distinguished Service to Atmospheric Sciences by an Individual is presented on the basis of activities which have materially contributed to the progress of the atmospheric sciences or to the application of atmospheric sciences to general social, economic or humanitarian welfare. The award is made occasionally.

The Sverdrup Gold Medal is granted to researchers who make outstanding contributions to the scientific knowledge of interactions between the oceans and the atmosphere. Friends of the late Harald Ulrik Sverdrup have established a Sverdrup Memorial Fund. As the Fund grows its activities will be expanded to honor Professor Sverdrup's name in other ways. The Medal will be awarded at suitable intervals. Unlike other awards, the Sverdrup Medal is awarded by the President of the Society on the advice of an international committee appointed in consultation with representatives of the Scripps Institution of Oceanography, La Jolla, Calif., and the University of Bergen, Bergen, Norway.

The Meisinger Award is made to an individual in recognition of research achievement that is, at least in part, aerological in character. Preference is to be given to promising atmospheric scientists thirty-five years of age or younger who have recently shown outstanding ability. This award is made annually.

The Award for Outstanding Service by a Weather Forecaster is presented to that member who through performance of exceptional forecast service has distinguished himself and brought credit to his profession. The Society makes the award in recognition of the great importance of weather forecasting to the public safety and well-being, and of the valuable professional services provided by its many members who are engaged in forecasting activities.

The Award for Applied Meteorology is made to an individual for outstanding contributions to the advance of applied meteorology. The contributions may lie in the direct application of meteorological or climatological knowledge to the fulfillment of industrial or agricultural needs or in research and development of scientific knowledge which can meet such needs. 
The Award for Outstanding Achievement in Bioclimatology is made to an individual who has made outstanding contributions in the field of bioclimatology. Recipient is nominated by the Awards Committee from a list submitted by the Committee on Biometeorology. Occasional award.

The Award for Outstanding Services to Meteorology by a Corporation is made to a corporation for contributions to the advancement of the science or the applications of meteorology. Award is made annually.

The Editor's Award is made to an individual who has contributed a referee's report of outstanding merit on a manuscript submitted for publication in one of the Society's journals. It draws attention to the facts that the quality of our journals depends in a crucial way upon the reviewing process, and that this process is one in which a large segment of the scientific community contributes much time and painstaking effort, largely unheralded, in a spirit of selfless commitment to the ideals of accuracy and lucidity in scientific writing. The award is made annually.

Special Awards and Citations are made to individuals or organizations, not appropriately recognized by more specifically defined awards, that have made important contributions to the science or practice of meteorology or to the Society. These honors are appropriate for individuals employed at other than the professional levelsuch as cooperative observers-and for amateurs who have made important contributions to meteorology. However, Special Awards may also be made to professional meteorologists for special accomplishments. Recipients may be nominated by the Awards Committee from lists submitted by local chapters or other interested members of the Society. Awards are made annually in such number as the Council may decide.

The Father James B. Macelwane Annual Awards in Meteorology are to be made at the annual meeting of the Society to the first, second, and third place winners in a student paper contest. The papers shall be original and shall be concerned with some phase of meteorology. Their purpose shall be to stimulate interest in meteorology among American college and university students. Registered students in an undergraduate school of a college or university in the Americas shall be eligible for participation, but no more than two students may enter contest papers from any one college or university. Judges for the final competition shall be appointed by the President of the Society. The first prize shall be $\$ 150.00$, the second prize $\$ 100.00$, and the third prize $\$ 50.00$.

The Howard T. Orville Scholarship in Meteorology is presented to a senior undergraduate meteorology major, who has completed at least 54 semester hours toward his Bachelor's degree, on the basis of academic excellence and achievement. This annual scholarship is $\$ 500.00$. The Orville Scholarship honors the late Howard T. Orville, Head of the Naval Aerological Service, 1940-1950, when he retired as Captain, USN. Captain Orville was president of the American Meteorological Society 1948-1949.

The Howard H. Hanks, Jr., Scholarship in Meteorology is presented to either a senior or a junior undergraduate meteorology major, who has completed at least 54 semester hours toward his Bachelor's degree, on the basis of academic excellence and achievement. This annual scholarship is $\$ 300.00$. The scholarship honors the late Howard H. Hanks, Jr., Vice President of Weather Corporation of America, who was engaged in applied and industrial meteorology at the time of his death in 1969. President William J. Hartnett of Weather Corporation of America provided funds for the scholarship.

\section{The Carl-Gustaf Rossby Award for Extraordinary Scientific Achievement}

\section{(Until 1958, designated as Award for Extraordinary Scientific Achievement)}

1951 Hurd Curtis Willett, "for his contributions to synoptic meteorology, and in particular to our understanding of the large-scale circulation patterns of the atmosphere."

1953 Carl-Gustaf Arvid Rossby, "for his contributions to dynamic meteorology leading to a better understanding of atmospheric motions and thermodynamics."

1955 Jerome Namias, "for his contributions to, and stimulation of, research in the principles and application of extended and long-range forecasting techniques." 
1956 John von Neumann, "for his farsighted contribution to the science of meteorology and the national interests in developing the modern, high-speed electronic computer with meteorological application as an ultimate aim, and for his support and encouragement in organizing the world's first research group in numerical weather prediction."

1960 J. Bjerknes and Erik Palmén, "for their pioneering and distinguished research contributions in atmospheric dynamics and synoptic aerology which have given a unified picture of the general circulation of the atmosphere."

1961 Victor P. Starr, "for his more than a decade of outstanding fundamental research leading to a better understanding of the general circulation of the atmosphere."

1962 Bernhard Haurwitz, "for the substantial advances due to his research in dynamic meteorology over a wide range of subjects, including among many the long waves in the westerlies, the circulation of the high atmosphere, local and diurnal effects, and hurricanes."

1963 Harry Wexler, posthumously, "for his contributions to knowledge of the atmosphere heat balance and dynamic anticyclogenesis, for his interdisciplinary studies in meteorology, oceanography, and glaciology and for his outstanding leadership in international programs in the atmospheric sciences."

\section{The Carl-Gustaf Rossby Research Medal}

1964 Jule G. Charney, "for his long and distinguished record of outstanding contributions to theoretical meteorology and related atmospheric sciences. Apart from acting as a strong scientific stimulus to the development of dynamical weather prediction, Professor Charney's research has led the way to a more fundamental understanding of the atmosphere's general circulation, hydrodynamical instability, the structure of hurricanes, the dynamics of ocean currents, the propagation of wave energy and many other aspects of geophysical fluid mechanics. In its scientific depth and breadth, Professor Charney's work has contributed significantly to the study of meteorology as an exact science."

1965 Arnt Eliassen, "for his many important contributions to dynamical meteorology, through which he has brought a new elegance and clarity into the subject. Noteworthy among these are his researches on free- and thermally-driven planetary circulations, on numerical weather prediction, on frontogenesis, and on shear and gravitational-acoustic wave propagation in stratified media."

1966 Zdenek Sekera, "for his numerous contributions to the dynamics of the atmosphere which comprise studies of waves at interfaces, of the dynamics of the atmospheric jet stream, and especially of the brightness and polarization of sky light in a scattering atmosphere which led to the extension and application of Chandrasekhar's general theory of radiative transfer to atmospheric problems. This work led to the computation of tables by Sekera and his co-workers. With the publication of these tables, in Chandrasekhar's words, 'the problem that was formulated by Rayleigh in 1871 has now at last found its complete solution.'"

1967 Dave Fultz, for "his outstanding and pioneering research over the past twenty years, which has resulted in laboratory experimental techniques in dynamic meteorology. Through example and personal instruction, these techniques have been the root of nearly all of the modeling studies of the general circulation that have been carried out to date."

1968 Verner E. Suomi, for "his imagination, ingenuity, and versatility in conceiving and designing divers meteorological sensors which have helped to transform the satellite as a meteorological probe from a dream to a reality. His Spin-Scan camera has given us our most comprehensive views of the atmosphere as an entity, and has already led to revised ideas concerning the circulation in lower latitudes."

1969 Edward N. Lorenz, for "his fundamental innovations in dynamic meteorology and his enlightening perspectives in advancing our understanding of the atmosphere as a physical system." 
1970 Hsiao-Lan Kuo, "for his fundamental research in atmospheric dynamics, beginning with his thesis on the stability of barotropic flow and continuing on the general circulation, the theory of hurricane formation, thermal convection, interaction of the atmosphere with the Earth's surface, and on many other topics of great importance."

1971 Norman A. Phillips, "for his introduction of new lines of study which have served to enlarge the scope of dynamic meteorology, his construction of a two-layer model making numerical prediction of developing systems feasible, and his diagnosis of nonlinear instability and prescription for dealing with it, permitting numerical simulation of the general circulation, which he had previously pioneered to be extended to infinite range."

1972 Joseph Smagorinsky, "for his creative leadership in numerical modeling of the general circulation of the atmosphere."

1973 Christian E. Junge, "for his productive investigations and international leadership in the study of atmospheric aerosols and atmospheric chemistry that have increased our knowledge of the stratospheric sulphate layer, the background tropospheric aerosol, the intricacies of marine aerosol distribution, and other topics important to the chemical budgets of the atmosphere."

1974 Heinz H. Lettau, "for his outstanding research achievements leading to a fuller understanding of the atmosphere's first mile. From his original concept of the stability length-scale to his pioneering contributions in boundary layer dynamics, turbulent transfer, climatonomy, and microscale surface modification, his work has been characterized by remarkable ingenuity and extraordinary dedication to purpose."

\section{The Second Half Century Award}

1970 Rudolph Hanel, Don T. Hilleary, Lewis D. Kaplan, and David Q. Wark, each cited "for his pioneering work in the development of the technique of procuring upper air soundings from Earth-orbiting satellites, culminating in the success of the infrared spectrometers on the Nimbus III satellite, which for the first time has provided data for global analyses of the temperature-pressure structure of the atmosphere."

1972 Richard J. Reed, "under whose leadership significant advances have been made in the understanding of the circulation and structure of mid-latitude and tropical atmospheres."

1973 Douglas K. Lilly, "for his theoretical, experimental, and observational contributions to the study of small-scale atmospheric phenomena including thermal convection, mountain waves, and turbulent interactions."

1974 James W. Deardorff, "for his many productive efforts toward furthering our understand. ing of turbulent processes in the planetary boundary layer through analytical studies and highly original numerical and laboratory experiments."

Tiruvalam N. Krishnamurti, "for his outstanding contributions to the fields of dynamic and synoptic meteorology including his diagnostic and prognostic studies of tropical and mid-latitude systems using real input data together with his enlightening analyses of tropical weather systems using satellite and aircraft information in sparse conventional data areas."

\section{The Charles Franklin Brooks Award for Outstanding Services to the Society}

(Until 1958, designated Award for Outstanding Services to the Society)

1951 Henry Southworth Shaw, "for his contributions to the welfare of the American Meteorological Society."

1953 Harry Guggenheim, "for establishing the first airways meteorological network in America and for his support of meteorological education and research." 
1955 Charles Franklin Brooks, "for a lifetime of devoted and untiring service to the Society, notably as its organizer in 1919, as its Secretary for the next thirty-four years, and as editor and mainstay of the BuLLETIN for most of its first twenty years."

1956 Robert Granville Stone, "for his many years of faithful editorship of the BulLETIN of the American Meteorological Society and his active participation in committee and council work."

1957 Carl-Gustaf Arvid Rossby, "for his great vision and tireless efforts in transforming the American Meteorological Society into an international scientific and professional organization."

1958 Henry Garrett Houghton, "for his important contributions in the growth of the American Meteorological Society through his guidance as President, as Secretary, and his unfailing service in Council and Committee work."

1960 Horace Robert Byers, "for his many years of unselfish and dedicated service to the Society as outstanding Councilor and President, and for advancing and broadening the international activities of the Society."

1961 Howard T. Orville, posthumously, "for his devoted and long-standing service to the Society as President, Councilor and staunch supporter of all its activities. His enthusiasm, zeal and personal dedication contributed much to the expansion of the Society."

1962 Sverre Petterssen, "for his untiring, unselfish and important contributions to the Society over a period of years as committeeman, Councilor and President."

1963 David M. Ludlum, "for his continuing effort, on behalf of the Society, to popularize meteorology and to stimulate the interest of young people in the field, for establishing WEATHERWISE, and for his effective participation in Society affairs over many years."

1964 Thomas F. Malone, "for his long, unstintingly and highly effective service to the scientific and professional aims of the American Meteorological Society. Acting as a member of the Society's Council, a member or chairman of many of its committees, Secretary of the Society, and finally as President of the Society, Dr. Malone has played a major part in framing the Society's response to the technological, social and scientific challenges of our time. These activities, together with Dr. Malone's service in the broader field of national scientific planning, policy and management, have been unique contributions to meteorology and the atmospheric sciences as a whole."

1965 Patrick D. McTaggart-Cowan, "for his long record of achievements in services to the Society, as Vice President, as Councilor, and as architect of the present organizational structure of the Society. Over the last two decades he has played a vital role in the advancement of the Society, both as a body of scientists and as an association of professional meteorologists. His excellently conceived blueprint for a new organizational structure is only one of many examples of his valuable services to the Society."

1966 John C. Beckman, "for his long and distinguished record of devoted service to the welfare and future development of our Society. As chairman of the Planning Commission he has devoted much thought and effort to the further advancement and progress of the Society, as a member of the Membership Committee he has given liberally of his time and his counsel, and as a member, he has freely donated advice and assistance of the highest caliber in furthering the funding programs of the Society."

1967 Phil E. Church, for his "outstanding service to the American Meteorological Society for over three decades during which time he has acted as a strong guiding force, always giving unstintingly of himself, and successfully striving to maintain the Society as a financially sound organization."

1968 Kenneth C. Spengler, for "his many contributions to the Society extending beyond those expected of the Executive Director, for the important part he had in the acquisition and restoration of the magnificent headquarters of the Society, and for his untiring efforts to have the Society keep pace with the great advances in the atmospheric sciences." 
1969 Alfred K. Blackadar, for "his dedicated service and continuing efforts in promoting the aims of the Society as editor, Secretary and Councilor with an unusual sense of human understanding."

1970 Robert Dawson Fletcher, "for two decades of unremitting and devoted service to meteorology, and to the American Meteorological Society through his work on committees, as Councilor, and as President."

1971 Louis J. Battan, "in recognition and appreciation of his imaginative, wise, and goodhumored leadership during many years of service as Councilor and President of the Society."

1972 Helmut E. Landsberg, "for his many contributions as Councilor, Fellow, and VicePresident of the American Meteorological Society and for his zeal and dedication in fostering cooperation between the Society and the national scientific community."

1973 Glenn R. Hilst, "for his leadership as Treasurer, Fellow, Editor of the Journal of Applied Meteorology, and Chairman of the Publications Commission in directing the goals of the Society toward the needs of its members and the goals of both toward the needs of mankind."

1974 David F. Landrigan, "in recognition of his devoted service to the Society for over a quarter century as legal and financial counsellor and in recent years as Secretary. Treasurer."

\section{The Cleveland Abbe Award for Distinguished Service to Atmospheric Sciences by an Individual}

1963 Lloyd V. Berkner, "for his scientific work on the upper atmosphere and for the stimu. lation he provided to the field of meteorology by his work as chairman of the Com mittee on Meteorology of the National Academy of Sciences."

1964 Francis W. Reichelderfer, "for his dedicated service to meteorology as Chief of the United States Weather Bureau. Over the past twenty-five years Dr. Reichelderfer has guided our nation's civil Weather Service through a difficult era of rapid technological and scientific innovation and equally rapid social and economic change. The fact that the U. S. Weather Bureau has steadily moved to keep pace with the changing demands and conditions of our time is in itself sufficient evidence of Dr. Reichelderfer's wisdom, statesmanship and foresight. We especially wish to express our own appreciation of his public service and his contributions to the Society's objectives."

1965 Sverre Petterssen, "for his outstanding contributions to the atmospheric sciences both as scientist and administrator. His papers and books have been guideposts for weather analysts and forecasters for more than a quarter of a century. His studies of convection and the dynamics of weather systems have assured him a high place among atmospheric scientists. Particularly noteworthy are his role in the preparation of a ten-year plan for a national effort in the atmospheric sciences and his leadership in developing a plan for an international program of research in the atmospheric sciences."

1966 Alan T. Waterman, "for his service to the Atmospheric Sciences as evidenced early in his scientific career by his contributions to the development of the single theodolite method for tracking pilot balloons to determine upper winds, and later by his many important actions to further the progress of meteorology as director of the National Science Foundation. Outstanding among these steps are his establishment of the Atmospheric Sciences program in the Foundation, his work on the Advisory Committee on Weather Control leading to the Foundation's interest in studies preparing a sound scientific basis for these activities, and his strong support of the university group recommending the establishment of a National Center for Atmospheric Research." 
1967 Arthur F. Merewether, for his "long and valuable service to the meteorological profession during which his influence in aviation meteorology has been a profound one, as an administrator, as a force to initiate change for progress, and as a pioneer pilot and meteorologist with breadth of vision in both military and commercial weather service."

1968 Thomas F. Malone, for "his innumerable contributions to meteorology as teacher, as scientific investigator, as editor, as committee member, as administrator, and always as innovator. From statistical weather forecasting to international cooperation, there is hardly an aspect of meteorology which has not experienced the benefit of his positive contributions."

1969 Robert M. White, for "distinguished scientific contributions to a better understanding of the general circulation, for exceptional administrative leadership in both the private and public sectors, and for wise and imaginative statesmanship in the international aspects of the atmospheric sciences."

1970 Walter Orr Roberts, "for his remarkable leadership in institutional building; for his contributions to the development of our learned societies, to the body of scientific knowledge and to the stimulation of interdisciplinary studies in meteorology and astronomy; and for his concerns with the impact of science and technology."

1971 Robert G. Fleagle, "for his scholarly achievements in the study of fluid dynamics and weather modification, his service to the nation in the Office of Science and Technology and in the National Academy of Sciences, and his valuable counsel for many years to the American Meteorological Society."

1972 Homer E. Newell, "for his many services to meteorology exemplified by his perception of problems and promising solutions in making key decisions regarding the meteorological satellite program, and by his skillful application of the review process during the formulation of national plans for weather modification research and the Global Atmospheric Research Program."

1973 Fred D. White, "for his dedication to advancing the cause of atmospheric science in both government and university forums through warm and personal efforts that transcend official duties."

1974 Lester Machta, "for outstanding contributions on critical atmospheric problems pertaining to the protection of the environment, especially for his studies of atmospheric constituents and pollutants including oxygen, carbon dioxide and radioactive material."

\section{The Sverdrup Gold Medal}

1964 Henry Stommel, "for his outstanding contributions to the dynamics of ocean currents, especially the Gulf Stream, and for the rich insight with which he has advanced knowledge of the physical nature of oceanic and atmospheric phenomena, ranging from the large-scale circulation of the oceans to cumulus clouds."

1966 Walter H. Munk, "for his outstanding contributions to the dynamics of wind-driven ocean circulations and wave phenomena on the surface of the sea."

1970 Kirk Bryan, "for his outstanding contributions to the numerical solutions of the general circulation of the oceans based on non-linear, three-dimensional models of the oceans driven by wind stress and differential heating."

1971 Klaus Hasselmann, "for his work on turbulence and his application of weak-coupling theory to a host of geophysical wave phenomena."

1972 Vladimir Kamenkovich, "for his extension of the Sverdrup transport equation to a general theory of ocean circulation, including the effects of island and coastal boundaries, linear and nonlinear." 
1938 Jerome Namias, "for application of thermodynamic tools to weather forecasting."

1941 Joseph J. George, “for fog forecasting studies."

1946 Morris Neiburger, "for studies of stratus clouds."

1947 Herbert Riehl, "for aerological studies in tropical and subtropical meteorology."

1948 James E. Miller, "for studies in vertical motion."

1949 Jule G. Charney and Arnt Eliassen, "for applying numerical methods to weather prediction."

1950 John Freeman, Jr., and Morris Tepper, "for their contributions in the application of hydraulic analogies to the study of meteorological phenomena including easterly waves, squall lines and tornadoes."

1951 Dave Fultz, "for application of experimental fluid mechanics to problems of atmospheric circulation."

1956 Ernest J. Fawbush and Robert C. Miller, "for their pioneering studies of the genesis and the practical prognosis of tornadoes and other destructive local storms."

1957 David Atlas, "for original and pioneering contributions in the field of radar meteorology."

1959 Robert G. Fleagle, "for his outstanding research contributions on the dynamics of the large-scale motions of the atmosphere."

1960 Philip D. Thompson and Norman A. Phillips, "for their theoretical and applied research in the field of numerical weather prediction."

1961 Verner E. Suomi, "for his imaginative and pioneering research work on atmospheric radiation problems in which he has effectively used both balloon and satellite observing platforms."

1962 Louis J. Battan, "for his outstanding, imaginative and pioneering research in radar meteorology and in cloud physics."

1962 Joanne Starr Malkus, "for her outstanding experimental work in cumulus investigation by means of aircraft measurement and for her imaginative use of these observations for deductions about the dynamics and energetics of cumulus clouds and about the role of convection in the general circulation of the tropics."

1963 Edward N. Lorenz, "for his introduction of concepts leading to a better understanding of the energetics of the general circulation, and for his recent work on low-order systems indicating aperiodic vacillations from one regime of motion to another."

1964 Richard J. Reed, "for his outstanding research in modern synoptic meteorology and dynamical weather prediction. Through his interpretations of natural meteorological events in the light of dynamical theory and through his descriptive analyses of otherwise unexplained or unsuspected phenomena, Professor Reed has contributed materially to the merging of the fields of synoptic and dynamical meteorology and to the development of a unified approach toward the study of atmospheric circulations."

1965 Hans A. Panofsky, "for his significant contributions to many branches of meteorology. His original and important researches have included the study of the atmospheres of planets other than the Earth and the challenging problems of atmospheric turbulence, especially in the planetary boundary layer." 
1966 George W. Platzman, "for his important contributions to the applications of fluid dynamics to the motions of the atmosphere and the waters of the Great Lakes. His work has done much to advance our knowledge of the long, planetary waves on the rotating Earth, and of atmospheric convection. His studies of the interaction between the atmosphere and the Great Lakes have very significantly improved our theoretical understanding and our ability to forecast the variations of the level of these important inland waterways."

1967 Tetsuya Fujita, for "pioneering research on the techniques of meso-meteorological analysis, for the new insights provided by such methods to our understanding of the mechanisms of severe local storms and tornadoes, and for broad contribution to the use of meteorological satellites."

1967 Joseph Smagorinsky, Syukuro Manabe, Yale Mintz, Akio Arakawa, and Cecil E. Leith, for "their outstanding individual and collective contributions to dynamic meteorology through their pioneering efforts to numerically model the dynamic behavior of the atmosphere by utilizing directly the primitive equations of motion."

1968 Katsuyuki Ooyama, for "his imaginative studies in the dynamics of tropical cyclones and other vortices, culminating in the successful generation of a simulated tropical hurricane by an electronic computer."

1969 Richard S. Lindzen, for "masterly insight and superb analysis which have lifted the veil from an ancient enigma, the atmosphere's diurnal tide."

1970 William L. Smith, for "developing a technique for converting satellite spectrometer measurements to vertical temperature profiles which permitted immediate operational use of the data."

1971 Joseph Pedlosky, "for his contributions to the fundamentals of dynamic meteorology and oceanography and to the general understanding of rotating, stratified fluids."

1972 Francis P. Bretherton, "for his important contributions to the theory of atmospheric motion, including the propagation of wave energy in shearing flow, the role played by critical layers in baroclinic instability and internal gravity waves, and the formation of true frontal discontinuities."

1973 Robert E. Dickinson, "for his prolific and imaginative work on a variety of problems concerning the dynamics of terrestrial and other planetary atmospheres."

James R. Holton, "for his important contributions to the study of rotating stratified fluids and the dynamics of the tropical atmosphere including the twenty-six-month oscillation and to the teaching of modern dynamic meteorology."

1974 Keith A. Browning, "for his broad contributions through the imaginative use of radar observations and their synthesis with other data thereby leading to significant new understanding of severe storms, hail, precipitation development, and clear air turbulence."

\section{The Award for Outstanding Service by a Weather Forecaster}

1967 Charles L. Mitchell, for "his record of outstanding public service during the first half of the 20th century. His generosity of spirit and remarkable talents mark him as a truly great representative of his contemporaries and as an example to forecasters of the present and future."

1968 Gordon E. Dunn, for "his outstanding and devoted public service in the performance and teaching of short-range weather forecasting in extratropical and tropical latitudes. Since assuming duty in Miami he has been the person upon whom the public has most directly depended for advice as to the course and development of each threatening Atlantic hurricane." 
1969 Lee George Dickinson, "in recognition of his imaginative and untiring efforts in the utilization of satellite meteorological information at the Asian Weather Central, Fuchu, Japan. By originating the facsimile transmission of the satellite data, arranging its exchange with Japan and training personnel of the various services, he made an outstanding contribution to weather forecasting in that area."

1970 Harlan K. Saylor, "in recognition of the extraordinary synoptic insight and forecasting skill which he has applied over many years to the effective blending of human judgment with machine calculation of the National Meteorological Center."

1971 Leonard W. Snellman, "for the excellence of his dynamic technical leadership of forecasting in the National Weather Service Western Region."

1972 Robert E. Clark, "whose sustained outstanding service while assigned to Detachment 11, 21 st Weather Squadron, Torrejon Air Base, Spain, contributed significantly to the Detachment's forecast capability."

1973 Hilmer Crumrine, "for accurate forecasts made during several of the most severe tornado outbreaks of modern times, namely those of 11 April 1965, 15 May 1968 and 21 February 1971, and for sustained excellence in aviation and public-service forecasting."

1974 W. Clyde Conner and Raymond H. Kraft, "for sustained excellence and outstanding performance in hurricane forecasting over the past quarter of a century, particularly for severe hurricanes in the Gulf of Mexico. In addition they have formulated systematic procedures for forecasting important hurricane related phenomena, such as storm surges and tornadoes, which have proven to be of great value in saving lives and property."

\section{The Award for Outstanding Contribution to the Advance of Applied Meteorology}

1956 Joseph J. George, "for his numerous contributions to the improvement of practical forecasting for airways operation, notably with respect both to general flight conditions and to local terminal conditions."

1957 Vincent J. Schaefer, "for his original contributions in the field of experimental and physical meteorology, particularly his pioneering work in artificial nucleation."

1959 Carl-Gustaf Arvid Rossby, posthumously. "He did much as President of the American Meteorological Society in 1944-1945 to convince industry of the importance of developing all phases of industrial meteorology and secured cooperation and support of large progressive companies in this effort. He persuaded the U. S. Weather Bureau to make weather information over teletype facilities available to private meteorologists without charge. He encouraged and inspired many younger meteorologists to enter the field of applied meteorology. In 1927 under the sponsorship of the Daniel Guggenheim Fund for Aeronautics he established the first model airway weather service in the United States."

1960 Henry T. Harrison, "for his pioneering work in aviation meteorology and his continuing key role in the development of modern aeronautical meteorology and its application to the jet era."

1961 Robert D. Elliott, "for his effective leadership and outstanding administration in broadly pursuing opportunities for expanding meteorological research and its applications in private industry."

1962 Alfred H. Glenn, "for his path-setting development in combining meteorological and civil engineering knowledge to form an effective approach for weather advice to industry, accepted as a basis for management decision." 
1963 Herbert C. S. Thom, "for a quarter century of contributions to applied meteorology, including furnishing climatological estimates to the armed forces during World War II, major contributions to the problems of statistical analysis of climatological data, development of wind design data, and development of a much improved formula for calculating annual and seasonal energy use for domestic heating."

1965 Loren W. Crow, "Certified Consulting Meteorologist, who is one of the first meteorologists to establish a successful business based solely on the private practice of consulting. Over the past several years, his many contributions to the Society, valuable services to his clients, and continued maintenance of the highest standards of professional ethics have reflected credit upon the Society and the profession as a whole and have greatly improved the stature of the consulting meteorologist."

1966 Eugene Bollay, "Certified Consulting Meteorologist, who has demonstrated imagination and technical skill in many areas of industrial meteorology, who has contributed generously to the affairs of the Society including its progress to better inform the public, and who, as an example of the private meteorological practitioner, has won the respect of the public and profession alike."

1967 Charles Pennypacker Smith, for his "pioneering contributions to the ethical development of the field of industrial meteorology and his continued support of the practice of consulting meteorology over the past two decades."

1968 Wallace E. Howell, for "his valuable contributions to the theory and practice of the modification of clouds by artificial nucleation. Over the years he has conducted many cloud-seeding operations, thereby helping to reveal both the effectiveness and the limitations of cloud-seeding procedures."

1969 E. Wendell Hewson, for "his pioneering work in the application of meteorology to the air pollution problems of industry and health."

1970 Arthur F. Merewether, "for his leadership in aviation meteorology and for his effective application of meteorology during World War II."

1971 George P. Cressman, "in recognition of his deep personal concern for the effective application of meteorology, and his skillful conversion of a broad knowledge of this science into more than two decades of outstanding service to the nation."

1972 Vincent J. Oliver, "for his innovative contributions over the past three decades in the application of new meteorological observations and theory to the problem of weather forecasting and for his creative use of meteorological satellite data."

1972 Howard B. Kaster, "for his pioneering contributions to the application of meteorological observations and theory to airline operations and the development of ocean routing procedures valuable to civilian and military ocean transportation."

1973 Harold A. Bedient, "for his contributions in the automation of global tropical analysis, flight planning, weather graphics and displays, weather data processing, communications, and computer operations."

Robert E. Munn, "for his extensive activities in the application of basic concepts of micrometeorology and atmospheric turbulence and diffusion to problems of air pollution, biometeorology and recently to the whole spectrum of international environmental problems."

1974 Robert A. McCormick, "for his remarkable national and international leadership in air pollution meteorology; for his foresight and initiative in bringing about global turbidity monitoring, advances in air quality simulation modeling, and productive urban air pollution field studies; and for his effectiveness in preserving a rigorous scientific approach in dealing with pressing applied problems." 


\section{The Award for Outstanding Achievement in Bioclimatology}

1960 Frederick Sargent, II, "for his success in organizing the field of bioclimatology in this country and for his outstanding studies on the effects of weather on man."

1963 Konrad J. K. Buettner, "for his distinguished and continuing studies on the influence of the atmospheric environment on man."

1964 Helmut E. Landsberg, "for his contributions to the science of bioclimatology and for his vigorous and effective efforts to bring attention to this field in proportion to its scientific and public importance. Dr. Landsberg not only has clarified the basic physical problems of determining the climate of the biosphere, but also has brought out clearly the main biological, ecological and medical factors of the microclimate that affect the health, happiness, efficiency and safety of the human organism. In view of the fact that man's knowledge should be applied primarily to man in his habitat, we wish to recognize our appreciation of Dr. Landsberg's efforts to increase our understanding of the normal human environment and its effect on our lives and activities."

1966 Frederick A. Brooks, "in recognition of his role as a prominent pioneer in the application of physical principles to problems of bioclimatology, particularly in regard to agricultural crops. To those working in this field, his studies of the radiation environments of plants, of heat transfer in the air near the ground, of the deposition of aerosols, and of the development of techniques for the benefit of agricultural productions are well known. His Introduction to Physical Microclimatology stands alone in its breadth and depth of treatment of these problems."

1967 Paul E. Waggoner, for his "outstanding contributions in relating microclimates to plant development and for the practical application of this knowledge to agricultural problems."

1969 William G. Wellington, "for bringing a unique combination of biological and micrometeorological insight to the study of insect biometeorology."

1971 David M. Gates, "for his comprehensive understanding, clear perspectives, and effective communication of concepts concerning the important relation between living organisms and their radiation environment."

1972 Igho H. Kornblueh, "for his systematic studies on the effects of ionized particles on human beings, and for his leadership in biometeorological research."

1973 Harold D. Johnson, "for his studies in environmental physiology relating to biologic responses of large and small animals to climate and other environmental factors."

\section{The Award for Outstanding Services to Meteorology by a Corporation}

1951 House Beautiful (Magazine) "for the far-reaching and highly stimulating work initiated by this magazine through the Climate Control Project."

1953 The Munitalp Foundation "for the far-reaching support devoted to many phases of meteorological activities."

1954 National Broadcasting Corporation "for performing an important public service through television coverage of the weather on its network programs, 'Today' with Dave Garroway and James Clayton Fidler and 'News Caravan' with John Cameron Swayze and John Clinton Youle."

1955 Science Service Inc. "for its extensive coverage and accurate reporting of current developments in theoretical and applied meteorology." 
1956 The New York Times "for its comprehensive editorial treatment and its consistently accurate reporting to the public of weather problems and weather news."

1957 The Travelers Insurance Companies "for their foresight, initiative, and courage in promoting and developing an entirely new field of specialized weather service for the American public."

1959 General Electric Company "for early recognition of the importance of meteorological phenomena in the operation of nuclear energy facilities and for bold and imaginative action by the Company's Hanford Atomic Products Operation in developing a continuing meteorological program uniquely adapted to the nuclear energy industry."

1960 American Airlines, Inc., Eastern Air Lines, Pan American World Airways, Inc., Trans World Airlines, and United Air Lines, "for their active support of the meteorological profession in maintaining their own specialized staff since the pioneering days of scheduled air service, and their many technical contributions to the field of aeronautical meteorology."

1961 Pacific Gas and Electric Company. "Pacific Gas and Electric Company has maintained an active support of private weather services since 1937. It is the first and probably only utility company in the United States that has made full use of weather facilities in its daily operations. It has also maintained an active interest in meteorology research and has made substantive contributions in this area."

1963 Radio Corporation of America "for contributions to meteorology through its role in producing the successful TIROS meteorological satellites."

1965 The Christian Science Monitor "for consistently doing an outstanding job in reporting news about the atmospheric sciences. This has been accomplished through the medium of on-the-spot stories of new developments as well as by extensive feature articles treating particular aspects of meteorology. The dual role of public service and education by this exceptional newspaper certainly makes it richly deserving of the Award for Outstanding Services to Meteorology by a Corporation."

1966 Industrial Laboratories of the International Telephone and Telegraph Corporation "for their contributions to the development of the high resolution radiometer flown on the Nimbus I which made nighttime images of the Earth's cloud cover from pole to pole quickly accessible. These pictures expressed as temperatures of the radiating surface give the meteorologist a new opportunity for a more quantitative analysis of the Earth's atmosphere."

1967 Atlantic Research Corporation for "developing of the meteorological rocket vehicle thereby permitting a significant vertical extension of man's ability to synoptically sound the atmosphere."

1968 Santa Barbara Research Center of Hughes Aircraft Company for "performing the intricate and exacting task of constructing the Spin-Scan camera, which has been borne aloft by high-level satellites. In the course of a few months its pictures have become familiar to the public, and have established the large cloud systems as the most prominent features of the Earth when viewed from space."

1969 Science Associates, Inc. for "its valuable services to the atmospheric sciences as professional consultants on instrumentation to government, education, industry and the public."

1970 A. H. Glenn \& Associates, Murray and Trettel, Inc., North American Weather Consultants, Northeast Weather Service, and Weather Corporation of America. Each was cited for "its pioneering the practice of private meteorology in the United States, thereby helping to develop an industry which has made significant contributions to the American economy."

1971 Scientific American, "for its recognition of the important roles played by atmospheric and oceanic processes in man's environment, and the effective communication of these concepts to the public." 
1972 General Electric Company, "for the contribution of its Space Division to the Nimbus satellite program in developing the spacecraft used to orbit important new meteorological satellite sensors, including those designed to sound the atmosphere on a global scale."

1973 WTVT Television Service of Tampa, Fla., "for outstanding performance in providing full coverage on television and through its own publications promoting meteorology, meteorological organizations, and support for weather activities by the public sector."

1974 Barnes Engineering Company, "for important contributions to the development of instruments and their applications in the field of infrared remote sensing of the Earth and atmosphere from ground-based, airborne, and space platforms."

\section{The Editor's Award}

1969 Norman A. Phillips, "for his referee's reports of outstanding merit on manuscripts submitted for publication in the Journal of THE AtmosPheric Sciences. In addition, he has had a most important influence in establishing and helping to maintain the high standards of JAS."

1970 Chester W. Newton, "for his referee's reports of outstanding merit on manuscripts submitted for publication in the Journal of Applied Meteorology. By such work the Society's journals are substantially improved."

1971 Peter V. Hobbs, "for his referee's reports of outstanding merit on manuscripts submitted for publication in both the Journal of the Atmospheric Sciences and Journal of APPLIED Meteorology."

1972 James W. Deardorff, "for his critical and conscientious review of manuscripts for the JOURNAL OF THE ATMOSPHERIC SCIENCES, resulting in considerable improvement in its scientific quality, and thereby contributing significantly to the high standards of the JOURNAL."

1973 George W. Platzman, "for his extraordinarily conscientious and comprehensive reviews on behalf of the Journal of Physical Oceanography."

1974 Norihiko Fukuta, "for his consistently detailed, knowledgeable and perceptive reviews for the Journal of Applied Meteorology. His constructive criticisms have surpassed simple criticism and have led to the strengthening of many manuscripts, and therefore of the Journal as a whole."

\section{Special Awards and Citations}

1957 Radio Station KSOK of Arkansas City, Kansas, "for its action in initiating a telephone call to the Weather Bureau Office in Wichita reporting that information has been received on tornadic activity near Maple City and Otto, Kansas. The tornado warning issued by the Wichita Office as a result of this call is believed to have saved the lives of at least six persons, possibly more."

1957 Television Station WKY-TV of Oklahoma City, Okla., "for their enthusiastic support of meteorology in their area. With a professional meteorologist serving as Publicity Director and Meteorologist for WKY-TV, the weather programs are found to be most interesting and emphasize progress made in meteorology. WKY-TV was also instrumental, several years back, in securing the reproduction rights to the now famous Corn Tornado movie film which they then made available to training agencies at cost."

1957 Joseph Bartatto, "for his action in reporting severe weather and rumbling sound, possibly a tornado, in his neighborhood. Relayed to the Green Bay Weather Bureau Office, the report was verified by the State Police and a general warning issued to alert other communities in central Wisconsin. It is reasonable to believe that a con. siderable number of lives were saved as a result of his timely report." 
1957 Stuart Grazier Bigler, "in recognition of his work during the Bryan, Texas, tornado of April 5, 1956. The timely warning which resulted from his study of the radar scope is believed to have saved the lives of a number of people that day."

1959 Maurice Levy, "in recognition of his courage and photographic ability in obtaining the outstanding movie of the Dallas tornado of April 2, 1957. This film has important scientific value since it is the first film that shows objects and debris in the tornado's circulation which can be followed in detail. Also, this film has been and will be used in tornado educational films which will lead to a better understanding by the public of the enormous fury of the tornado."

1959 Jean Felix Piccard, "in recognition of his pioneering work in developing balloons for high altitude research."

1960 U. S. Forest Service, "for its progressive approach in conducting studies of the effects of weather on the national forest resources."

1960 Charles B. Moore, Malcolm D. Ross, and posthumously, Lee Lewis, "for their recent and significant work in making important aerophysical observations from highaltitude balloons."

1960 Walter Rue, "for the outstanding work in writing feature articles on the subject of weather and climate."

1960 Nicholas Brango, "for his pioneering work in hurricane tracking and forecasting which has provided the basis for improved hurricane reconnaissance and warning methods."

1961 William W. Kellogg and Stanley M. Greenfield, "for their pioneering work in the planning of a meteorological satellite."

1961 John C. Freeman and Archie M. Kahan, "for their pioneering work in the establishment of the Tornado Warning Radar Network."

1962 Werner A. Baum, "for his successful leadership in developing the Journal of MeteoROLOGY into a large publication of high international stature over a decade of very demanding editorial effort."

1964 Dean Blake, "for his distinguished service to meteorology over more than sixty years. Both in his half century of activity in the U. S. Weather Bureau at San Diego, including thirty years as Meteorologist in Charge, and his subsequent years of supposed retirement, during which he has served as consultant to the San Diego Department of Public Health, Mr. Blake has contributed notably to the advancement of the science of meteorology, the public understanding of its nature and significance, and the practical benefits of its application. In particular his studies of the structure and behavior of the temperature inversion over the California coast, published in 1928, were the first analysis of this important phenomenon. His courses in meteorology at San Diego State College have introduced the subject to many who subsequently made their careers in meteorology. For these many contributions over a long and outstanding career the American Meteorological Society presents a Special Award to Mr. Blake."

1964 Reverend Adelhelm Hess, O.S.B., "in recognition of his long and devoted service as a cooperative weather observer for the United States Weather Bureau. Voluntarily and without recompense, Father Hess has faithfully made observations at Conception, Mo., for over sixty years. For his contribution to the national climatological record and to the total fund of research data, the American Meteorological Society presents this special award to Father Hess."

1965 Gordon D. Cartwright and Morton J. Rubin, "for their important contributions to international cooperation in meteorology. For almost a decade they have been concerned with international undertakings in meteorological research. During the International Geophysical Year each one spent a year at the Main Soviet Antarctic Station working with scientists from the Soviet Union. By their professional competence and 
personal characteristics they have done a great deal to enhance the image of American scientists."

1966 Mrs. Gertrude M. Woods, "for her more than sixty years of devoted service as the official cooperative weather observer at Palmetto, Tennessee, continuing a family record begun in 1883 by her father. She was honored by the Weather Bureau for the faithful performance of her voluntary duty with the John Campanius Holm Award in 1960, with the Thomas Jefferson Award in 1965, and by President Johnson in a letter commending her for 'the careful collection of weather data over so long a period' and for her "unselfish dedication in this important task." "

1969 Fortune Magazine and Lawrence Lessing, for "the article 'Doing Something About the Weather-In a Big Way,' which, in providing an accurate and balanced account of current efforts of the world meteorological community to establish a global observational and research program aimed at extending the range and accuracy of weather predictions, exemplifies popular scientific writing at its best."

1969 Station KICD, Spencer, Iowa, "in recognition of its public service in broadcasting during the period of severe weather over northwest Iowa on June 13, 1968, advisories which were instrumental in saving lives."

1970 Hydrologic Services of the ESSA Weather Bureau, "for providing early forecasts and warnings of the spring floods of 1969 in the upper midwest part of the nation, thereby permitting advance cooperative action by federal, state and local authorities and preventing great damage and loss of life."

1970 Ferdinand C. Bates, posthumously, "for his pioneering efforts in severe storm research, and for his outstanding contribution to applied meteorology."

1970 Howard H. Hanks, Jr., posthumously, "for his tireless efforts in research and applied meteorology and especially for his generosity in giving of himself and his ideas to others."

1970 WIMAQ-TV, Chicago, Ill., "for outstanding public service in disseminating timely weather information particularly on severe storms."

1971 George L. Hammond, "for his imaginative and effective leadership of the technically challenging application of forecasts to ship routing at the United States Navy Fleet Weather Central, Alameda, California."

1971 Robert E. Cardinal, "for his forecasting skill and sensitivity to the needs of the public as meteorologist in charge of the National Weather Service Office at Klamath Falls, Oregon."

1971 National Broadcasting Company, “for its 'Today' television program for the excellent presentation of meteorological information which educates the public on the nature of weather and the importance of protecting the public against its hazards."

1971 WKY Television System, Incorporated, of Oklahoma City, "for its sense of public responsibility in making available to the National Severe Storms Laboratory its transmitter tower for the study of the atmospheric layer near the ground."

1971 Raymond E. Falconer and Raymond A. Wrightson, "for their imaginative exhibits on the Weather Services Centennial for the Albany, N.Y., area."

1972 Robert Jastrow, “for his dedication and achievement as first editor of the Society's Journal of THE ATMospheric Sciences in guiding its development and growth to its present position as a leading national scientific publication and in broadening its scope of interest to include aeronomy and planetary atmospheres."

1972 Francis W. Reichelderfer, "in appreciation of his lifetime of devotion to the American Meteorological Society as charter member, Fellow, and President" and "for his countless contributions to the weather services of the United States and the world." 
1972 Malcolm Rigby, for his devoted and untiring service as the Editor of the Society's MetEOROLOGICAL AND GeOASTROPHYSICAL ABstracts since its initiation in 1950 and for his dedicated work on the documentation and retrieval of geophysical data."

1973 Agricultural (Fruit Frost) Weather Forecasters in Arizona and California, "in recognition of outstanding weather forecasts and advisory services to the agro-business interests in California and Arizona during the winter seasons of 1971 and 1971-1972 which enabled owners to reduce losses of agricultural products substantially."

1973 William H. Best, Jr., "for unswerving dedication and support to principles of the American Meteorological Society as exemplified by his promotion of close cooperation among the weather services and encouragement of greater Air Weather Service participation in the Society's activities."

1973 James W. Reid, posthumously, "for originating and producing the program 'How's the Weather' on the TN Radio Network for over thirty years and for his efforts in organizing the North Carolina Chapter of the American Meteorological Society."

1974 Illinois State Water Survey, "for initiation, support and successful completion of imaginitive research in applied meteorology dealing with storm, rainfall, and hail patterns, weather modification, and related hydrometeorological problems."

\section{The Father James B. Macelwane Awards in Meteorology}

1960 William E. Shenk, Pennsylvania State University, "Guidance-Vector System of Forecasting Hurricane Motion." (First Prize)

Joel Myers, Pennsylvania State University, "Snowfall Variations in Philadelphia." (Second Prize)

Francis P. W. Ho, University of Hawaii, "The Possibilities of Fresh Water Fish Cultivation in Southern Viet-Nam." (Third Prize)

1963 John B. Armstrong, University of British Columbia, "Forest Fire Forecasts, Fire Weather, and the Fire Danger Index in British Columbia." (First Prize)

Francis W. Lemire, Assumption University, Windsor, Ont., "Winds on the Great Lakes." (Second Prize)

1964 Charles B. Pyke, University of California, Los Angeles, "The Role of Air-Sea Interactions in the Development of Cyclones." (First Prize)

Miss Marlies Oberlander, University of California, Los Angeles, "On the Heat Transport by Ocean Currents." (Second Prize)

Walter A. Lyons, Saint Louis University, "Radiation, TIROS III, and the Mesoscale." (Third Prize)

Edward E. Hindman, II, University of Utah, "Development of a Continuous Natural Supercooled Cloud Particle Chamber." (Honorable mention)

1965 William L. Woodley, University of California, Los Angeles, "Computations of Cloud Growth Related to the Seeding of Tropical Cumuli." (First Prize)

John R. Dickson, Texas A\&M University, "A Study of Similarity Profiles of Temperature and Wind Speed in the Atmospheric Boundary Layer." (Second Prize)

Edward E. Hindman, II, Colorado State University, "The Phase Change in an Artificial Supercooled Cloud upon Heterogeneous and Homogeneous Nucleation." (Third Prize)

Joseph Hilary Golden, University of California, Los Angeles, "The Potential Dewpoint Field as a Forecast of Convective Precipitation." (Honorable mention)

1966 Edward E. Hindman, II, Colorado State University, "Theoretical Investigation of 
Techniques Using Dry Ice for the Dissipation of Supercooled Fogs -4C and Warmer." (First Prize)

Ann E. Gargett, University of Manitoba, Winnipeg, Canada, "Long Term Fluctuations in the Toronto Temperature and Precipitation Record." (Second Prize)

D. W. Hartlieb, State University of New York, Fredonia, "Ground Observations of Warm Cloud Emission." (Third Prize)

1968 Peter H. Hildebrand, University of Chicago, "An Examination of a Cumulus Cloud Width-Height Measure Under the Effects of Seeding." (First Prize)

Andrew J. Heymsfield, State University of New York, Fredonia, "Snow Crystal Types Observed in Snow Squalls." (Second Prize)

1969 I. R. Graham, University of Toronto, Canada, "An Analysis of Turbulence Statistics at Fort Wayne, Indiana." (First Prize)

Victor F. Morris, University of Washington, "A Study of Mesoscale Mountain Barrier Effects in Western Washington and Vancouver Island." (Second Prize)

Andrew J. Heymsfield, State University of New York, Fredonia, "Redistribution of Snowfall in Lake Effect Snow Squalls by Ridges and Valleys to the Lee of Lake Erie." (Third Prize)

1970 Andrew J. Heymsfield, State University of New York, Fredonia, "Snow Crystal Analysis of the Effectiveness of Seeding a Lake Erie Snow Squall on December 14, 1966." (First Prize)

Carlyle H. Wash, University of Wisconsin, "The Formation of a Convective Layer During Cyclogeneses." (Second Prize)

Boris Weisman, Downsview, Ontario, Canada, "Air Pollution Survey for Hamilton, Ontario." (Third Prize)

1971 Dean G. Duffy, Case Institute of Technology, "Approximate Analytic Solution to the Growth of Nonfreezing Droplets in a Supersaturated Updraft." (First Prize)

Sharon E. Nicholson, University of Wisconsin, "Paleographic Reconstructions and Possible Circulation Patterns from Cambrian to Quaternary Periods." (Second Prize)

1972 Robert M. Friedman, New York University, "On the Influence of Traveling Planetaryscale Waves on Absorption in the Lower Ionosphere." (First Prize)

1973 Louis W. Uccelini, University of Wisconsin, "Surface Divergence and Convergence Fields Associated with Mid-Western Convective Systems." (First Prize)

Mary Ann Hrivnak, Pennsylvania State University, "Fog Dispersal Methods Applicable to Harrisburg-York Airport." (Second Prize)

Douglas Beadle, Kirkwood Community College, Cedar Rapids, Ia., "Reliability of the Analogue Method in Long-Range Forecasting." (Third Prize)

1974 Robert M. Thompson, Jr., Florida State University, "The Diurnal Variability of Severe Local Storms in New England." (First Prize)

David B. Gilhousen, Florida State University, "An Initialization Scheme for a Hurricane Model." (Second Prize)

\section{The Howard T. Orville Scholarship in Meteorology}

1965 Daniel L. Smith, Florida State University.

1966 James P. Charba, University of Texas. 
1967 Robert L. Gall, Pennsylvania State University.

1970 Allen C. Dittenhoefer, Cornell University.

1971 Cary B. Schudy, Florida State University.

1972 Lawrence J. Lewis, New York University.

1973 John A. Pollack, Pennsylvania State University.

1974 John A. Toth, Pennsylvania State University.

The Howard H. Hanks, Jr., Scholarship in Meteorology

1973 Robert M. Thompson, Jr., Florida State University.

1974 Daniel Keyser, Pennsylvania State University. 